\title{
Health care needs of cancer survivors in general practice: a systematic review
}

\author{
Renske A Hoekstra, Marianne J Heins ${ }^{*}$ and Joke C Korevaar
}

\begin{abstract}
Background: The number of cancer survivors is increasing due to improved treatments. Consequently, general practitioners will treat more and more cancer survivors in the upcoming years. Only little is known about the care needs of these survivors and guidelines to support general practitioners in their treatment of these patients are lacking. The aim of this study was to gain insight in the health care needs of cancer survivors in general practice.

Methods: A systematic review on cancer survivors' general practice needs was conducted in PubMed, Embase and the Cochrane Library of Systematic Reviews. Eligible studies could be qualitative or quantitative studies examining cancer survivors' needs in general practice. Studies of adult survivors, with any cancer type, considered free of active disease and no longer receiving active treatment, were included. For each study a quality score was given using a form developed specifically for this study. Statements about survivors' general practice needs were collected and corresponding themes were grouped.
\end{abstract}

Results: Fifteen studies were included, of which twelve were qualitative. Most mentioned general practice needs were psychosocial needs, mainly being support received form the GP, followed by a need for help with medical issues, and a need for information on cancer, recovery, late treatment effects and on adjusting to life after treatment.

Conclusions: Cancer survivors have different types of general practice needs that are currently not or insufficiently met. This review provides a starting point for the development of new guidelines for general practitioners to support in cancer survivorship.

Keywords: Cancer survivors, Care needs, Primary health care, General practitioner, Family physician

\section{Background}

The incidence of cancer is increasing, which is partly due to the aging population [1]. In addition, because of improved treatment options and detection at an early stage, the five-year survival rate of cancer has increased in recent years $[2,3]$. Consequently, the number of cancer survivors is increasing. The term 'cancer survivor' covers a wide range of patients: from those who have just finished their active treatment period to patients who have been discharged from follow-up for years.

Cancer survivors have more health problems compared to age and sex matched controls [4], which may last for many years after completion of the treatment. These health problems constitute a broad spectrum including infections, chronic diseases, minor illnesses

\footnotetext{
* Correspondence: m.heins@nivel.nl

Netherlands Institute for Health Services Research (NIVEL), P.O Box 1568,
} 3500 BN Utrecht, The Netherlands

and psychosocial problems, such as sleep disturbance and depression [5]. As a consequence, cancer survivors visit their general practitioner more often than non-cancer controls [6-9]. Despite this higher health care utilization, cancer survivors indicate that they still have health care needs that are unmet $[10,11]$. Apparently, these patients have specific needs that current aftercare does not meet sufficiently $[10,11]$.

To attain better general practice for cancer survivors, clinical guidelines for cancer survivorship care need to be developed, as reported by the Institute of Medicine and other national councils [12,13]. For this purpose, more clarity on survivors' health care needs are necessary [14]. Besides care for previously mentioned medical and psychosocial problems, studies in secondary care showed that cancer survivors have needs for informational and emotional support [15-17]. Systematic research on all these needs in general practice is still missing. The purpose 
of this systematic review is to report how adult cancer survivors describe their care needs in the general practice environment.

\section{Methods \\ Data collection}

In September 2012, we searched three databases: MedLine, Embase and the Cochrane Library of Systematic Reviews. The search combined cancer-related terms with terms related to follow-up care, health care needs and general practice (Additional file 1). With 'care needs' we mean what cancer survivors want to receive for their health problems, and from whom. Only papers written in English or Dutch were included.

Title and abstract of all articles were independently scanned on inclusion criteria (see below) for eligibility by two researchers $(\mathrm{RH}, \mathrm{MH})$. Full texts of all articles rated as potentially relevant were obtained. Authors were approached for articles not available in full text. Full text of the articles was assessed by two researchers ( $\mathrm{RH}, \mathrm{MH})$ to see whether it met the inclusion criteria. In case the two researchers disagreed about eligibility for inclusion, this was discussed until consensus was reached. If no agreement was reached, a third author (JK) was asked to make a decision.

\section{Inclusion criteria were:}

- Original peer-reviewed study (no case reports, review, editorials, letters, conference abstracts etc.)

- Full text obtainable

- Written in English or Dutch language

- Population: o consists (mainly) of cancer patients; $\circ$ consists of adults ( $>18$ years);

o patients are in follow-up care or are not actively treated anymore.

- Results:

$\circ$ are obtained by either questionnaires or interviews (individually or in groups);

o describe (care) needs;

o contain data about specific needs for general practice.

\section{Papers included \\ $\mathrm{n}=15$}

Additional studies were identified by reviewing the reference list of all included studies, of reviews found in our search, and by expert referral.

\section{Quality assessment}

As a validated quality assessment instrument for both quantitative and qualitative studies does not exist, as far as we know, we could not use existing checklists to assess the quality of the included studies. We therefore made a checklist based on common elements from existing checklists (Additional file 2) [18-22]. We selected those elements from the existing lists that were applicable to our study.

Two reviewers ( $\mathrm{RH}, \mathrm{MH})$ independently assessed study quality using the checklist and they resolved differences by discussion. If no agreement was reached, a third reviewer (JK) was asked to make a decision. A quality score was calculated by giving 1 point for each met criterion and dividing this by the maximum obtainable score.

\section{Analysis and synthesis}

We first assembled statements and quotes from the results sections of the qualitative studies concerning survivors' needs in general practice. We used qualitative synthesis to aggregate and summarise results of the included study. We sought to identify and group overlapping themes and subthemes of needs. The results of the quantitative studies were then categorised into the same themes as those identified in the qualitative studies.

Quality assessment was used to identify the impact of lower scoring studies. We re-analysed our results, using only studies with a quality score higher than $70 \%$, which we considered an acceptable score.

\section{Results}

Figure 1 shows the flowchart of the study selection. Finally, 15 studies were included in our study; [23-37] 12 were obtained by database search, the remaining three by expert referral and reviewing references. All included studies were published between 1990 and 2012. Searching in the Cochrane Library revealed two reviews, which were excluded based on the title. Study characteristics are shown in Table 1. Most of the included studies were qualitative studies $(n=12)$, whereas three studies contained quantitative data from surveys. Of the qualitative studies, most were based on individual semi-structured interviews (66\%) with relatively small sample sizes (between 6 and 44 participants). The quantitative studies had considerably larger sample sizes (32-431). Most studies were conducted in a country where many people have a general practitioner and the general practitioner plays an important role as gatekeeper for secondary care, such as the United Kingdom and Denmark. The majority of all participants was between 50 and 80 years old. Although we only included studies with adult participants, we made an exception for Cheung et al [35],. in which the age range started at 16 years. Because the number of participants was relatively high and mean age was 57 years, we decided to include this study.

The themes that were identified involved medical, psychosocial and informational needs, need for proactive contact and a group called other. Psychosocial needs were the most frequently mentioned needs; they were 


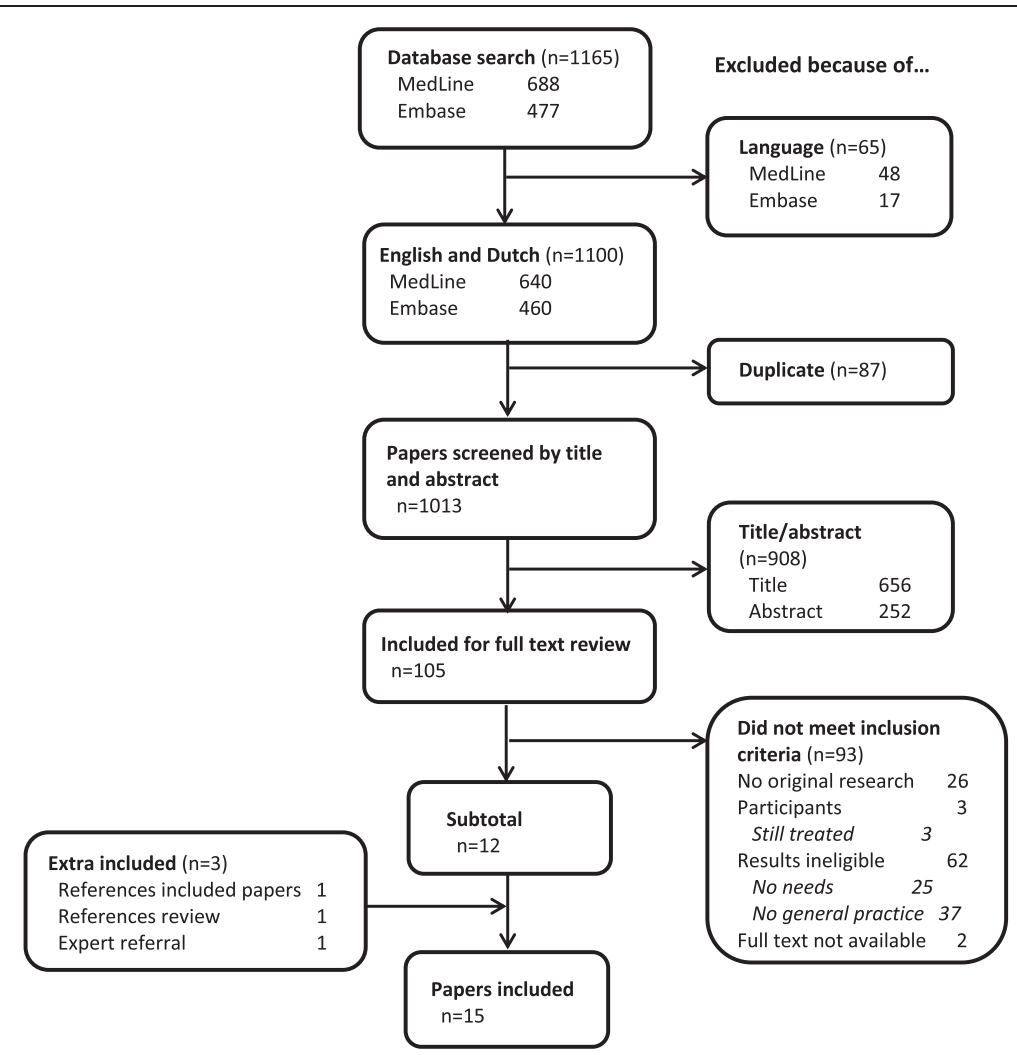

Figure 1 Flowchart of the study selection.

mentioned in 12 out of 15 studies (see Table 2). Most studies reported the importance of the general practitioner as a supporter and someone to share ideas and concerns with. The general practitioner was seen as providing "warmth, encouragement and emotional support", with familiarity as an important aspect of this support [32]. Some studies mentioned that participants were feeling too embarrassed to discuss feelings and problems with a specialist, and rather talked about this with their general practitioner [32,34].

Eleven studies outlined the need for help from the general practitioner regarding medical issues. Survivors saw a main role for the general practitioner in treating non-cancer-related medical problems and general preventive healthcare. Regarding cancer-related care they mainly saw a role for the GP in helping with common (late) treatment effects.

The need for information was much-discussed, with a large variety in topics: eight studies reported eleven different information needs. Most described needs were those related to getting information about cancer and recovery: patients spoke about the GP "answering questions" $[34,37]$ and "explaining cancer in lay terms" [24] and "need for more information" [30], in which was not specified which information they would like. Concerning the long-term period, patients wanted information "particularly relating to late effects of cancer treatment" [30]. They also indicated a need to "discuss adjusting to life after treatment" [29] and asked therefore to know more about local peer support groups.

In a small number of studies, four out of 15 , cancer survivors mentioned that they would appreciate a proactive approach of their general practitioner, especially shortly after diagnosis or after the end of treatment. This could be either a call or an offer for a contact initiated by the general practitioner.

\section{Sensitivity analysis}

Quality assessment for each study is listed in Additional file 3. Mean quality score was $70 \%$. One study (Eardley et al. [25]) met less than $50 \%$ of the quality criteria. Four criteria were unmet in most studies: 'describing reason for qualitative approach', 'describing and considering role of the researchers', 'avoiding selection bias' and 'describing counterexamples'.

Limiting our analyses to the articles with a score above $70 \%$ (8 out of 15 ) would have influenced our results. Medical and informational needs would be the most mentioned needs, and psychosocial needs would drop down to third place. 
Table 1 Study characteristics

\begin{tabular}{|c|c|c|c|c|c|c|c|}
\hline Author \& year & $\begin{array}{l}\text { Study } \\
\text { design* }\end{array}$ & Nr. of participants & $\begin{array}{l}\text { Mean age at } \\
\text { interview** }\end{array}$ & Sex: male (\%) & $\begin{array}{l}\text { Cancer } \\
\text { type*** }\end{array}$ & Specification of cancer type** & $\begin{array}{l}\text { Study } \\
\text { country }\end{array}$ \\
\hline \multicolumn{8}{|l|}{ Qualitative studies } \\
\hline Eardley 1990 [25] & । & 44 & 71 & 91 & Mix & bladder and prostate & UK \\
\hline Hudson 2012 [26] & 1 & 42 & $65(47-80)$ & 43 & Mix & 24 breast, 18 prostate & USA \\
\hline Khan 2011 [30] & I & 40 & $\begin{array}{l}20 \%<6025 \% 61-70 \\
40 \% 71-8015 \%>81\end{array}$ & 45 & Mix & 15 breast, 13 CRC, 12 prostate & UK \\
\hline Rozmovits 2004 [33] & । & 39 & $60(33-87)$ & 51 & CRC & & UK \\
\hline Adams 2011 [24] & I & 38 & $\begin{array}{l}21 \%<5037 \% 50-70 \\
42 \%>70\end{array}$ & 50 & Mix & $\begin{array}{l}9 \text { breast, } 6 \text { prostate, } 4 \text { CRC, } \\
4 \text { head/neck, } 3 \text { lung, } \\
3 \text { melanoma, } 2 \text { testis, } \\
2 \text { gynaecologic, } 2 \text { Hodgkin, } \\
1 \text { NHL, } 1 \text { bladder, } 1 \text { renal }\end{array}$ & UK \\
\hline Norman 2001 [32] & I & 25 & $58(28-84)$ & 44 & Mix & $\begin{array}{l}11 \text { primary cancer sites, most } \\
\text { common: breast and lung }\end{array}$ & Canada \\
\hline Kantsiper 2009 [28] & G & 21 & - & 0 & Breast & & USA \\
\hline Sahay 2000 [34] & I & 20 & $65(48-87)$ & - & CRC & & Canada \\
\hline Aabom 2009 [23] & $1^{\wedge}$ & 16 & $65(50-80)$ & 75 & Mix & 6 rectum, 8 colon, 2 pancreas & Denmark \\
\hline Kendall 2006 [29] & G & 16 & $53(35-70)$ & 50 & Mix & $\begin{array}{l}3 \text { breast, } 3 \text { bowel, } 3 \text { haematological, } \\
2 \text { prostate, } 1 \text { testis, } 1 \text { Hodgkin, } \\
1 \text { lung, } 2 \text { unknown }\end{array}$ & UK \\
\hline Lydon 2009 [31] & G & 6 & $64(52-73)$ & 0 & Ovarian & & UK \\
\hline Jiwa 2006 [27] & G & - & - & - & Breast & & \\
\hline \multicolumn{8}{|l|}{ Quantitative studies } \\
\hline Cheung 2009 [35] & - & 431 & $57(16-91)$ & 27 & Mix & $\begin{array}{l}216 \text { breast, } 43 \text { genitourinary, } \\
39 \text { hematologic, } 30 \text { gastrointestinal, } \\
26 \text { head/neck, } 21 \text { lung, } 17 \\
\text { gynaecologic, } 28 \text { other, } 21 \\
\text { unreported }\end{array}$ & USA \\
\hline Sisler 2004 [37] & - & 200 & $\begin{array}{l}16 \% \leq 49 \quad 17 \% 50-59 \\
30 \% 60-6937 \% \geq 70\end{array}$ & 45 & Mix & $\begin{array}{l}54 \text { breast, } 39 \text { prostate, } 24 \text { CRC, } \\
25 \text { lung, } 14 \text { reproductive organs, } \\
56 \text { other }\end{array}$ & Canada \\
\hline De Padova 2011 [36] & - & 32 & $36(22-60)$ & 100 & Testis & & Italy \\
\hline
\end{tabular}

- = not mentioned/not applicable.

${ }^{*} \mathrm{I}=$ individual; ${ }^{\wedge}=$ together with next of kin; $\mathrm{G}=$ group.

${ }^{*} \mathrm{CRC}=$ colorectal cancer, $\mathrm{NHL}=$ non-Hodgkin's lymphoma.

\section{Discussion}

\section{Summary}

This study is the first systematic literature review that addresses the care needs of adult cancer survivors in the general practice setting. Cancer survivors' health care needs in general practice focus mainly on psychosocial support, i.e. discussing the impact of their disease, medical help, mostly for non-cancer related problems, and getting general information about their disease. These are all tasks that a general practitioner is used to perform.

The majority of existing studies on care needs of cancer survivors focused on needs in secondary care or to needs in general. Two literature reviews in secondary care showed a need for psychosocial, medical and informational support $[38,39]$. Yet, it is not specified in these reviews from whom they want to get this support. Results of these studies are in line with those of our review. This indicates that the type of support that survivors want from their general practitioner covers a large part of their health care needs.

\section{Strengths and limitations}

Our study has some limitations. First, the search strategy was limited by searching in three databases. These are, however, the most prominent in the medical field; it seems therefore unlikely that searching in other databases would have provided many additional articles. Secondly, the search strategy was performed some time ago, so new papers may have been published in the mean time. Third, we might have an under-presentation of all existing needs, since five out of fifteen included articles did not have 'needs' as a main topic [23,31,32,34,37]. However, we probably revealed the most important needs by reviewing several articles about this subject. 
Table 2 General practice needs in cancer patients

\begin{tabular}{|c|c|c|}
\hline Type of need & $\begin{array}{l}\text { Nr. of studies } \\
\text { reporting } \\
\text { this need* }\end{array}$ & Studies \\
\hline Psychosocial needs (total) & 12 & \\
\hline Support & 7 & {$[23-25,29,31,32,34]$} \\
\hline $\begin{array}{l}\text { Discussing psychosocial } \\
\text { impact of cancer }\end{array}$ & 6 & {$[23,25,29,34,36,37]$} \\
\hline $\begin{array}{l}\text { Talking about difficulties in } \\
\text { relationships }\end{array}$ & 4 & {$[23,28,29,36]$} \\
\hline Other subtopics & 4 & {$[24,25,27,30]$} \\
\hline $\begin{array}{l}\text { Need for medical issues } \\
\text { (total) }\end{array}$ & 11 & \\
\hline $\begin{array}{l}\text { Non-cancer-related } \\
\text { medical problems }\end{array}$ & 7 & {$[25,26,30,32,35-37]$} \\
\hline (Late) treatment effects & 4 & {$[28,29,34,37]$} \\
\hline Other subtopics & 5 & {$[24,26,29,35,36]$} \\
\hline Informational needs (total) & 8 & \\
\hline $\begin{array}{l}\text { Answering questions/general } \\
\text { information }\end{array}$ & 6 & {$[24,25,30,31,34,37]$} \\
\hline Long-term effects/management & 3 & {$[24,30,34]$} \\
\hline Peer support groups & 3 & {$[24,29,33]$} \\
\hline Other subtopics & 2 & {$[24,29]$} \\
\hline $\begin{array}{l}\text { Need for proactive contact } \\
\text { (total) }\end{array}$ & 4 & \\
\hline $\begin{array}{l}\text { Proactive contact from } \\
\text { general practitioner }\end{array}$ & 3 & {$[24,29,37]$} \\
\hline Designated appointment & 2 & {$[24,28]$} \\
\hline $\begin{array}{l}\text { Encouragement to contact the } \\
\text { PCP with questions }\end{array}$ & 1 & [29] \\
\hline Other needs (total) & 8 & \\
\hline $\begin{array}{l}\text { Financial and practical } \\
\text { issues }\end{array}$ & 4 & {$[24,25,28,29]$} \\
\hline Referrals to specialists & 4 & {$[25,32,34,37]$} \\
\hline $\begin{array}{l}\text { Care for caregivers and } \\
\text { family }\end{array}$ & 4 & {$[27,29,32,37]$} \\
\hline Other subtopics & 1 & [34] \\
\hline
\end{tabular}

*Subthemes were only listed when they were mentioned in at least one third of the studies that discussed the main theme. For 'total', studies that discuss the smaller subtopics not listed in the table, are also included.

Another limitation is that the method of quality assessment we used has not been validated, since a validated assessment tool that is both applicable for qualitative and quantitative studies does not exist. Our assessment is, however, based on existing lists, like the checklist from the Critical Appraisal Skills Programme and the RATS guidelines for Biomed Central. The impact of the study quality seems limited, as our sensitivity analyses showed that, although the order of care needs altered after applying stricter criteria, the content of the themes did not change.

We included studies from different countries with a variety of health care systems. These differences may influence expectations and needs regarding general practice, but given the relatively small number of studies on this subject we decided to pool them in our analyses. Post-hoc analyses showed some interesting differences. Studies from the UK, where general practice has an important role in health care, mainly focused on psychological and informational needs. They also frequently mentioned financial needs. Those from Canada, where general practice also has a prominent role, mentioned a large variety of needs. They were the only ones mentioning the need for referral to specialists. In contrast, studies from the USA, where general practice has a less prominent role, mainly mentioned medical needs.

We reviewed qualitative as well as quantitative studies. This posed challenges to the aggregation and description of our results, but it also led to an interesting finding as we found some notable differences and similarities in outcome between these two study types. Need for psychosocial, medical and informational support were mentioned in both study types, but their relative importance differed. In qualitative studies psychological needs were an important topic, while in quantitative studies medical needs were a main topic. These differences are probably due to the study designs. In quantitative studies patients are often provided with a restricted number of options. This enables a more structured needs assessment, but patients may not be able to mention all needs they have. Qualitative studies might provide more options to express specific opinions, which could lead to a larger variety of mentioned needs, and they may also be more suitable to discuss psychological needs.

\section{Conclusion}

We uncovered several domains on which cancer survivors have needs in general practice: medical, psychosocial, informational and proactive contact. Based on the results of this review we cannot say to what extent these needs are currently met, but it could be helpful if general practitioners are aware of these needs of their own patients and thus can adjust to them in the care given during the continuing survivorship period. Stanton et al. showed that patients do not spontaneously report all needs and ask all questions to their GP and that few doctors systematically ask for common problems [40]. A more proactive attitude of physicians could help in assessing patients' needs.

This review also showed that the few studies assessing adult cancer survivors needs in the general practice setting are diverse, both in their quality and study topics. A more systematic way of collecting needs info is needed to guide GPs and their teams in caring for the increasing number of cancer survivors. 


\section{Additional files}

\section{Additional file 1: Search terms. \\ Additional file 2: Quality assessment list. \\ Additional file 3: Quality assessment.}

\section{Competing interests}

The authors declare that they have no competing interests.

\section{Authors' contributions}

$\mathrm{RH}$ performed the literature search and selection of relevant papers, aggregated results, drafted the manuscript. $\mathrm{MH}$ participated in the design of the study, selected relevant papers, aggregated results and helped to draft the manuscript. JK participated in the design of the study, aggregated results and helped to draft the manuscript. All authors read and approved the final manuscript.

\section{Received: 17 February 2014 Accepted: 2 May 2014}

Published: 13 May 2014

\section{References}

1. Gommer AM: Kanker samengevat. In Volksgezondheid Toekomst Verkenning, Nationaal Kompas Volksgezondheid. 2012 [http://www.nationaalkompas.nl/ gezondheid-en-ziekte/ziekten-en-aandoeningen/kanker/].

2. Siesling $\mathrm{S}$, Visser $\mathrm{O}$, Luth TK, Karim-Kos HE, van de Poll-Franse LV, Aben KK, Damhuis RA: Volwassen kankerpatiënten overleven langer in Nederland: 5-jaarsoverleving 12\% toegenomen tussen 1989-1993 en 2004-2008. Ned Tijdschr Geneeskd 2011, 155(12):A3169.

3. Verdecchia A, Francisci S, Brenner H, Gatta G, Micheli A, Mangone L, Kunkler I, EUROCARE-4 Working Group: Recent cancer survival in Europe: a 2000-02 period analysis of EUROCARE-4 data. Lancet Oncol 2007, 8(9):784-796.

4. Stein KD, Syrjala KL, Andrykowski MA: Physical and psychological long-term and late effects of cancer. Cancer 2008, 112(11 Suppl):2577-2592.

5. Heins M, Korevaar J, Rijken P, Schellevis F: For which health problems do cancer survivors visit their general practitioner? Eur J Canc 2013, 49(1):211-8

6. Heins M, Schellevis F, Rijken M, van der Hoek L, Korevaar J: Determinants of increased primary health care use in cancer survivors. J Clin Oncol 2012, 30(33):4155-4160

7. Khan NF, Watson E, Rose PW: Primary care consultation behaviours of long-term, adult survivors of cancer in the UK. Br J Gen Pract 2011, 61(584):197-199.

8. Mols F, Helfenrath KA, Vingerhoets AJJM, Coebergh JW, van de Poll-Franse L: Increased health care utilization among long-term cancer survivors compared to the average Dutch population: a population-based study. Int J Canc 2007, 121(4):871-877.

9. Nord C, Mykletun A, Thorsen L, Bjoro T, Fossa SD: Self-reported health and use of health care services in long-term cancer survivors. Int J Canc 2005, 114(2):307-316.

10. Soothill K, Morris SM, Harman J, Francis B, Thomas C, Mclllmurray MB: The significant unmet needs of cancer patients: probing psychosocial concerns. Support Care Canc 2001, 9(8):597-605.

11. Harrison SE, Watson EK, Ward AM, Khan NF, Turner D, Adams E, Forman D, Roche MF, Rose PW: Primary health and supportive care needs of long-term cancer survivors: a questionnaire survey. J Clin Oncol 2011, 29(15):2091-2098.

12. Life CoCSICaQo, Council loMaNR: From Cancer Patient to Cancer Survivor: Lost in Transition. Washington, DC: National Academies Press; 2005.

13. Kankerbestrijding SKK: Nazorg bij kanker: de rol van de eerste lijn. Den Haag: KWF Kankerbestrijding; 2011.

14. von Meyenfeldt M, Boersma L, Maessen J, Keymeulen K: Follow-up in oncology: focused on the patient and the disease. Ned Tijdschr Geneeskd 2011, 155(45):A4127.

15. Sanson-Fisher R, Girgis A, Boyes A, Bonevski B, Burton L, Cook P: The unmet supportive care needs of patients with cancer. Supportive Care Review Group. Cancer 2000, 88(1):226-237.

16. Liao MN, Chen MF, Chen SC, Chen PL: Healthcare and support needs of women with suspected breast cancer. J Adv Nurs 2007, 60(3):289-298.
17. Vivar CG, McQueen A: Informational and emotional needs of long-term survivors of breast cancer. J Adv Nurs 2005, 51(5):520-528.

18. Kuper $A$, Lingard $L$, Levinson W: Critically appraising qualitative research. BMJ 2008, 337:a1035.

19. Law M, Stewart D, Letts L, Pollock N, Bosch J, Westmorland M: Guidelines for Critical Review Form - Qualitative studies; 2007. Version 2.0: [http://www.srsmcmaster.ca/Portals/20/pdf/ebp/qualguidelines_version2.0.pdf.]

20. Programme CAS. Qualitative Research Checklist; 2010 [http://www.casp-uk.net/ wp-content/uploads/2011/11/CASP_Qualitative_Appraisal_Checklist_14oct10. pdf]

21. Clark J: The RATS Guidelines Modified for BioMed Central; 2012 [http://www. biomedcentral.com/authors/rats]

22. Zwieten M, Willems D: Waardering Van Kwalitatief Onderzoek. Huisarts en Wetenschap 2004, 47(13):38-43

23. Aabom B, Pfeiffer P: Why are some patients in treatment for advanced cancer reluctant to consult their GP? Scand J Prim Health Care 2009, 27(1):58-62.

24. Adams E, Boulton M, Rose P, Lund S, Richardson A, Wilson S, Watson E: Views of cancer care reviews in primary care: a qualitative study. $\mathrm{Br} J \mathrm{Gen}$ Pract 2011, 61(585):173-182.

25. Eardley A: Patients' needs after radiotherapy, the role of the general practitioner. Fam Pract 1990, 7(1):39-42

26. Hudson SV, Miller SM, Hemler J, Ferrante JM, Lyle J, Oeffinger KC, Dipaola RS: Adult cancer survivors discuss follow-up in primary care: 'not what i want, but maybe what i need'. Ann Fam Med 2012, 10(5):418-427.

27. Jiwa M, Thompson J, Coleman R, Reed M: Breast cancer follow-up: could primary care be the right venue? Curr Med Res Opin 2006, 22(4):625-630.

28. Kantsiper M, McDonald EL, Geller G, Shockney L, Snyder C, Wolff AC: Transitioning to breast cancer survivorship: perspectives of patients, cancer specialists, and primary care providers. J Gen Intern Med 2009, 24(Suppl 2):S459-S466.

29. Kendall M, Boyd K, Campbell C, Cormie P, Fife S, Thomas K, Weller D, Murray SA: How do people with cancer wish to be cared for in primary care? Serial discussion groups of patients and carers. Fam Pract 2006, 23(6):644-650.

30. Khan NF, Evans J, Rose PW: A qualitative study of unmet needs and interactions with primary care among cancer survivors. Br J Canc 2011, 105(Suppl 1):S46-S51.

31. Lydon A, Beaver K, Newbery C, Wray J: Routine follow-up after treatment for ovarian cancer in the United Kingdom (UK): patient and health professional views. Eur J Oncol Nurs 2009, 13(5):336-343.

32. Norman A, Sisler J, Hack T, Harlos M: Family physicians and cancer care Palliative care patients' perspectives. Can Fam Physician 2001, 47:2009-2006.

33. Rozmovits L, Rose P, Ziebland S: In the absence of evidence, who chooses? A qualitative study of patients' needs after treatment for colorectal cancer. J Health Serv Res Pol 2004, 9(3):159-164.

34. Sahay TB, Gray RE, Fitch M: A qualitative study of patient perspectives on colorectal cancer. Cancer Pract 2000, 8(1):38-44.

35. Cheung WY, Neville BA, Cameron DB, Cook EF, Earle CC: Comparisons of patient and physician expectations for cancer survivorship care. J Clin Oncol 2009, 27(15):2489-2495.

36. De Padova S, Rosti G, Scarpi E, Salvioni R, Amadori D, De Giorgi U: Expectations of survivors, caregivers and healthcare providers for testicular cancer survivorship and quality of life. Tumori 2011, 97(3):367-373.

37. Sisler JJ, Brown JB, Stewart M: Family physicians' roles in cancer care. Survey of patients on a provincial cancer registry. Can Fam Physician 2004, 50:889-896.

38. Schmid-Buchi S, Halfens RJG, Dassen T, van den Borne B: A review of psychosocial needs of breast-cancer patients and their relatives. J Clin Nurs 2008, 17(21):2895-2909.

39. Rutten LJF, Arora NK, Bakos AD, Aziz N, Rowland J: Information needs and sources of information among cancer patients: a systematic review of research (1980-2003). Patient Educ Couns 2005, 57(3):250-261.

40. McCool J, Morris J: Focus of doctor-patient communication in follow-up consultations for patients treated surgically for colorectal cancer. J Manag Med 1999, 13(2-3):169-177.

\section{doi:10.1186/1471-2296-15-94}

Cite this article as: Hoekstra et al:: Health care needs of cancer survivors in general practice: a systematic review. BMC Family Practice 2014 15:94. 